\title{
CAMINHANDO COM O PSICODRAMA ON-LINE
}

\author{
Marisa Becil Ferreira ${ }^{1, *}$ [D
}

\section{RESUMO}

O objetivo geral do presente artigo é contextualizar o Psicodrama no modelo de intervenção psicoterápica on-line, e o objetivo específico é demonstrar a viabilidade do atendimento psicodramático on-line com adultos a partir de descrições de sessões sociátricas por meio dessa modalidade. Os recursos psicodramáticos utilizados nas sessões sociátricas em destaque são Jogos dramáticos, Psicodrama Interno, Psicoterapia da Relação e Psicodrama Bipessoal com dramatização em cena aberta. Os resultados obtidos confirmam que o Psicodrama rompe a conserva da necessidade da psicoterapia presencial para que a sociatria ocorra, abrindo espaço para novos caminhos.

PALAVRAS-CHAVE: Psicodrama; On-line; Intervenção.

\section{WALKING WITH ONLINE PSYCHODRAMA}

\begin{abstract}
The general objective of this article is to contextualize Psychodrama in the online psychotherapeutic intervention model, and the specific objective is to demonstrate the viability of online psychodramatic care with adults from the description of sociatric sessions through this modality. The psychodramatic resources used in the highlighted sociatric sessions are Dramatic Games, Internal Psychodrama, Relationship Psychotherapy and Bipersonal Psychodrama with dramatization in an open scene. The results obtained confirm that Psychodrama breaks the need for face-to-face psychotherapy for sociatrics to occur, opening space for new paths.
\end{abstract}

KEYWORDS: Psychodrama; Online; Intervention.

\section{CAMINANDO CON PSICODRAMA EM LÍNEA}

\section{RESUMEN}

El objetivo general de este artículo es contextualizar el Psicodrama en el modelo de intervención psicoterapéutica online, y el objetivo específico es demostrar la viabilidad de la atención psicodramática online con adultos a partir de la descripción de sesiones sociológicas a través de esta modalidad. Los recursos psicodramáticos utilizados en las sesiones sociátricas destacadas son Juegos Dramáticos, Psicodrama Interno, Psicoterapia de Relaciones y Psicodrama Bipersonal con dramatización en escena abierta. Los resultados obtenidos confirman que el Psicodrama rompe con la necesidad de la psicoterapia presencial para que ocurra la sociatría, abriendo espacios a nuevos caminos.

PALAVRAS CLAVE: Psicodrama; En línea; Intervención.

\footnotetext{
1.Associação Brasiliense de Psicodrama e Sociodrama, Brasília (DF), Brasil.

*Autora correspondente: marisa.becil@yahoo.com.br

Editor de Seção: Marlene Marra

Recebido: Set. 03, 2020 | Aceito: Jan. 13, 2021
} 


\section{INTRODUÇÃO}

A maioria dos psicoterapeutas psicodramatistas, dentre os quais me incluo, estão sendo desafiados a fazer Psicodrama clínico on-line, em virtude das orientações da Organização Mundial da Saúde (OMS), que determina o distanciamento social e a não aglomeração para evitar a dissiminação da Covid-19. Dia a dia, enfrentamos conservas estabelecidas de que as sessões sociátricas devem ser apenas presenciais e de que não é possível dramatizar por meio do virtual.

Pesquisas internacionais afirmam que o uso de tecnologias de comunicação e informação tem se mostrado positivamente útil no tratamento de pacientes (Barbeiro \& Reis, 2018), mas no Brasil a permissão para que os psicólogos atendam on-line é recente. $\mathrm{O}$ atendimento por meio de TI foi regulamentado pelo Conselho Federal de Psicologia (CFP, 2018), a partir da Resolução n. ${ }^{\circ}$ 11/2018, que permite o atendimento psicológico on-line para consultas de avaliação, orientação e/ou intervenção, seleção de pessoal, supervisão técnica e aplicação de testes psicológicos aprovados pelo Sistema de Avaliação de Testes Psicológicos (SATEPSI), excetuando-se as situações de emergência e urgência. Porém, em virtude da pandemia do coronavírus, o CFP (2020) lançou a Resolução n. ${ }^{\circ} 4$,

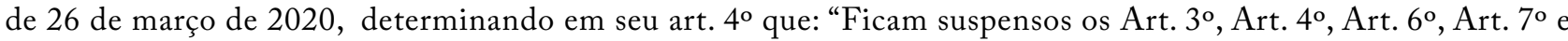
Art. $8^{\circ}$ da Resolução CFP no 11, de 11 de maio de 2018, durante o período de pandemia do Covid-19 e até que sobrevenha Resolução do CFP sobre serviços psicológicos prestados por meios de tecnologia da informação e da comunicação", no sentido de que, para fazer atendimento online, os psicólogos têm de se inscrever no Cadastro e-Psi, mas sem necessidade de aguardar confirmação de cadastro no e-Psi, podendo também atender os pacientes em situação de emergência e/ou urgência.

Dentre os estudiosos e pesquisadores da Psicologia, vários termos foram cunhados para a modalidade on-line, como telepsicologia (APA, 2013), telepsicoterapia (Judge et al., 2011) e telepsicodrama (Fleury, 2020).

Como o Psicodrama on-line é possível? De quais métodos e técnicas psicodramáticos podemos fazer uso para exercermos nosso papel de psicoterapeuta psicodramatista? A partir de perguntas tão prementes, temos de buscar respostas criativas e espontâneas. Esse é o objetivo maior deste trabalho ao descrever sessões sociátricas com adultos na modalidade on-line. Esse caminho não é fácil, mas o convido a percorrê-lo comigo.

\section{O PRIMEIRO PASSO}

Após fazer o cadastro no e-Psi do Conselho Federal de Psicologia, ao sermos procurados por um cliente, temos de fazer o contato pré-terapia, por meio de telefone, e-mail, mensagem de Instagram etc., para conversar sobre nossa abordagem, a disponibilidade, o pagamento e a escolha de como atender o paciente na modalidade on-line (plataforma).

Em seguida, há a necessidade da formalização de um contrato por escrito com assinatura ou o de acordo do paciente, tendo a atenção de que, para crianças e adolescentes, deve haver o consentimento expresso de ao menos um dos responsáveis legais (CFP, 2018).

\section{O CAMINHAR COM O PACIENTE}

$\mathrm{Na}$ primeira sessão on-line, procuro perceber como o paciente está se sentindo ao utilizar a plataforma escolhida para a psicoterapia, mostrando o meu ambiente e pedindo para que ele me fale onde está, para nos tranquilizarmos com relação à privacidade e ao sigilo durante o tratamento. Em seguida, explico como utilizar a plataforma e, juntos, conversamos e decidimos o que fazer caso haja problemas de conexão, buscando outras possibilidades de contato.

Ao nos conectarmos com o paciente na modalidade on-line, nossa atenção é dirigida para o além do verbal, com foco em seu timbre de voz, em sua fisionomia, em sua respiração e em seus demais movimentos. O caminhar com o paciente no seu ritmo, na busca de uma relação mais télica, propicia a confiança e o vínculo necessários na relação paciente-terapeuta, para que ocorra o encontro (Fonseca, 2008). 


\section{A TEMÁTICA DA PANDEMIA}

Os primeiros contatos da psicoterapia on-line são carregados da temática coronavírus, sendo importante o acolhimento do paciente, que expõe seu mundo interno, em sua grande maioria, a partir de pensamentos automáticos disfuncionais, sentimentos de ansiedade e medo e sensações físicas diversas como falta de ar e tensão muscular. Tenho trazido alguns recursos de outras abordagens como a psicoeducação (Fadden, 2002), com o objetivo de explanar as orientações da Organização Mundial da Saúde, de médicos e de pesquisadores sobre a pandemia, e construir um projeto de uma rotina positiva, com destaques para os aspectos físicos e mentais, levando em contas as peculiaridades do paciente e o meio em que ele se encontra, dando ênfase à necessidade de higiene adequada, alimentação nutricional, exercícios físicos, bem como de estabelecer divisão do tempo entre labor e lazer.

\section{COMO ACHAR O CAMINHO}

De acordo com Moreno (1993), a espontaneidade nos leva à criatividade, tão necessária aos psicoterapeutas, seja numa sessão presencial, seja numa on-line. As etapas da sessão sociátrica on-line seguem as etapas clássicas da sessão presencial, que são o aquecimento, a dramatização e o compartilhar (Vidal \& Castro, 2020).

Como refere Pio Abreu (2006), ao iniciar a sessão, podemos utilizar o aquecimento inespecífico verbal ao perguntar como tem sido o dia a dia do paciente, o que ele quer trazer de relevante desde o nosso último encontro e, por fim, o que ele quer trabalhar. Podemos também fazer aquecimentos inespecíficos corporais, como caminhar no local onde ele está, alongar-se e exercícios de respiração, mas inevitavelmente também perguntando o que ele quer trabalhar (Cukier, 2008).

O aquecimento específico pode ser um relaxamento se o terapeuta for utilizar o Psicodrama Interno (Fonseca, 2010) ou a montagem da cena aberta com objetos intermediários para uma dramatização (Cukier, 2018).

Tenho me valido, no Psicodrama on-line, da técnica de videoteipe (Fonseca, 2018), ao pedir que o protagonista feche os olhos, entre contato com o seu sentimento e traga uma cena para o momento do aqui e agora, em que este sentimento esteja presente para começar a dramatização. Em outros momentos, utilizo a Psicoterapia da Relação, a partir dos papéis internalizados do protagonista (pai, mãe, chefe etc.), com a utilização de duplos-espelhos (Fonseca, 2010). Outro recurso interessante é a técnica da escultura, que propicia ao paciente o não racional e, consequentemente, o despertar da emoção. Os jogos dramáticos (Yozo, 1996) são muito eficientes no atendimento on-line, podendo o diretor usá-los como método, seguindo as três etapas para a operacionalização de uma sessão psicodramática, ou como aquecimento em si para a dramatização. Vários jogos podem ser usados on-line, como átomo pessoal, átomo familiar, átomo social, dando nós, jogo do contorno, cadeira vazia, fotografia, linha do tempo etc. (Vidal \& Castro, 2020).

No atendimento on-line, o aquecimento para dar início à dramatização e se manter constante durante as cenas é produzido por meio dos iniciadores corporais, emocionais e ideativos (Perazzo, 2005).

Por fim, o compartilhar traz a possibilidade de autopercepção do paciente e, quando acontece na psicoterapia de grupo, “cada um precisa sentir em que ponto foi tocado pela dramatização" (Bustos, 2005, p. 91).

\section{RELATOS TERAPÊUTICOS}

\section{Caso I}

No retorno de um atendimento de grupo de apenas dois pacientes, a primeira sessão on-line não teve um protagonista, mas sim um tema protagônico: a pandemia. Começamos a sessão explicando a plataforma escolhida para o nossos encontros on-line, tirando as dúvidas de todos no grupo. Em seguida, perguntei se estavam confortáveis para prosseguirmos e se estavam em um lugar com privacidade. Eles disseram que sim. Também mostrei meu espaço de trabalho, com o objetivo de demonstrar que cada sessão sociátrica on-line seria da responsabilidade de todos com relação ao sigilo e à privacidade do grupo. Conversamos como estava sendo a vida de cada um do grupo a partir do isolamento social. Os pacientes detalharam 
o dia a dia deles em casa. Após o relato de cada um dos participantes do grupo - o aquecimento inespecífico verbal - dei a consigna de que fizessem uma escultura com as mãos sobre a relação eu-pandemia, em que a mão dominante seria o "eu" e a mão não dominante, a "pandemia". As duas esculturas apareceram na tela, e pedi para tirar uma foto, de modo que eu tivesse um registro delas para uma futura confrontação entre o antes e o depois, em outro momento. No atendimento presencial, ocupo o lugar do paciente para que ele veja sua própria escultura, ou seja, aplico a técnica do espelho (Cukier, 2018). No atendimento on-line não há essa necessidade, pois cada um do grupo se vê na tela. Assim, a técnica do espelho acontece simultaneamente a cada movimento. As esculturas foram exploradas da seguinte forma:

Terapeuta: Esculturas muito significativas. José (nome fictício), ao ver a escultura de Rita (nome fictício), qual é a sua percepção dessa escultura?

Paciente José: Parece um monstro atacando uma pessoa.

Terapeuta: Rita, ao ver a sua própria escultura, o que vem a sua mente?

Paciente Rita: Algo que é maior do que eu e que está me deixando muito ansiosa.

Terapeuta: $\mathrm{O}$ que ou quem pode te ajudar nessa situação?

Paciente Rita: Eu mesma.

Terapeuta: O que você pode fazer?

Paciente Rita: Não exigir tanto de mim, colocar limites no meu home-office.

Terapeuta: Muito bem! Podemos ir para a outra escultura?

Paciente Rita: Sim.

Terapeuta: Rita, ao ver a escultura do José, o que vem à sua mente?

Paciente Rita: Uma mão parece um muro, e a outra, um soco.

Terapeuta: José, o que você percebe ao ver a sua escultura?

Paciente José: Realmente, um muro. Não consigo fazer as coisas. Muitas coisas que estou vendo na internet me paralisam.

Terapeuta: Quem ou o que pode te ajudar?

Paciente José: Tenho de me organizar e ser mais estável na minha rotina da quarentena.

Terapeuta: Podemos conversar um pouco agora sobre os recursos que temos para lidar melhor com a quarentena e a pandemia?

Pacientes Rita e José: Sim.

Após a dramatização, no compartilhar, cada um colocou seus recursos, e falei sobre a rotina positiva na quarentena com relação a aspectos físicos e mentais (psicoeducação).

\section{Caso 2}

Em um atendimento de Psicodrama Bipessoal on-line, a paciente relata, no início da sessão, que teve uma conversa com seu filho na qual ele disse que o cuidado dela o estressa. Ela diz que não esperava isso dele, nas palavras dela, "do meu menino", que chorou bastante e se pergunta como fazer diferente. A partir da nossa conversa (aquecimento inespecífico verbal), pergunto se ela gostaria de trabalhar a relação dela com o filho. Com a concordância da paciente, a sessão continua:

Terapeuta: Hoje você falou que seu filho disse que seu cuidado com ele o estressa. Feche os olhos e busque na sua memória uma cena em que você esteja cuidando do seu filho. Quando a cena estiver na sua mente, abra os olhos.

Paciente abre os olhos.

Terapeuta: Descreva onde você está e quem está com você. 
Paciente: Estou na minha casa com meu filho.

Terapeuta: O que você está fazendo?

Paciente: Estou cuidando do meu filho, pois ele está aprendendo a andar e tenho de ficar perto dele para ajudá-lo.

Terapeuta: Qual a idade do seu filho?

Paciente: Ele tem 11 meses.

Terapeuta: Você quer falar algo para ele?

Paciente: Sim. A mamãe está aqui para te ajudar, meu menino.

Terapeuta: Feche os olhos de novo e procure na sua memória outra cena em que você esteja ajudando seu filho.

Paciente abre os olhos.

Terapeuta: Onde você está agora? Quem está com você?

Paciente: Estou na escola do meu filho. Vim aqui para conversar com a diretora sobre meu filho. Ele está sofrendo

bullying, e preciso ajudá-lo.

Terapeuta: Qual a idade do seu filho?

Paciente: Ele tem 13 anos.

Terapeuta: Ele sabe que você está aqui?

Paciente: Sim.

Terapeuta: Ele não se importa?

Paciente: Não.

Após essa cena, em que a paciente fala com a diretora da escola, peço mais uma vez que ela feche os olhos e busque na sua memória mais alguma cena de cuidado com o filho. A paciente traz outra cena em que seu filho tem 17 anos e está com dificuldades de se adaptar à faculdade. Mais uma vez, ela o ajuda. Finalmente, a paciente traz a cena que culminou na sua pergunta de como fazer diferente.

Terapeuta: Onde você está e quem está com você?

Paciente: Estou na garagem da minha casa com meu filho.

Terapeuta: Quantos anos seu filho tem?

Paciente: Ele tem 30 anos.

Terapeuta: Eu gostaria de conversar com seu filho. Você pode ser seu filho a partir de agora?

Paciente: Sim.

Terapeuta: João (nome fictício), você está fazendo o que nesta garagem?

Paciente no papel de seu filho João: Estou tirando o carro da garagem.

Terapeuta: E o que a sua mãe está fazendo?

Paciente no papel de seu filho João: Ela está me dizendo como tirar o carro da garagem, como se eu não soubesse dirigir.

Terapeuta: Você gostaria de falar algo para ela?

Paciente no papel de seu filho João: Sim. Eu sei dirigir, mãe. Não precisa ficar falando exatamente o que tenho de fazer (Fala em tom alto e com raiva).

Terapeuta: Volte agora a ser você, Maria (nome fictício). O que você sente ao ouvir seu filho falar isso com você?

Paciente: Eu estou muito assustada com o modo como ele falou comigo. Eu não esperava essa reação dele.

Terapeuta: Você quer falar algo para ele?

Paciente: Eu sei que tenho de deixar você fazer as coisas do seu jeito e não do meu. Vou tentar fazer isso.

Após a dramatização, durante o compartilhar, pergunto se ela percebe que chama João, que tem 30 anos, de "meu menino". A paciente relata que sim e que também percebe que seu filho é um adulto e que tem de tratá-lo como um adulto. Esse é o desafio dela nas suas palavras. 
O relato dessa sessão on-line demonstra como a técnica do videoteipe (Fonseca, 2018) é utilizada para manter o aquecimento desde a cena primeira até a última.

\section{Caso 3}

Esta paciente iniciou a psicoterapia já na modalidade on-line. $\mathrm{Na}$ sua $11^{\mathrm{a}}$ sessão, ela relata ter a sensação de ser uma impostora em vários papéis. Ao ser perguntada no sentido de quais papéis seriam esses, ela diz: "Sinto-me uma farsa no papel de psicóloga, de aluna de pós-graduação e até de esposa”. Peço que ela escolha um papel para trabalharmos essa sensação de impostora, e ela escolhe o papel de estudante de pós-graduação. Em seguida, utilizo o Psicodrama da Relação (Fonseca, 2010) a partir da técnica do duplo-espelho e a relação "eu-eu":

Terapeuta: Você traz a sensação de ser uma farsa como estudante de pós-graduação. É isso?

Paciente: Sim, não só como estudante, mas também como psicóloga e até como esposa.

Terapeuta: Você poderia detalhar mais essa sensação?

Paciente: Tenho de fazer uma prova a cada 15 dias do meu curso de especialização, inclusive posso consultar os livros, mas tenho uma sensação de que não sei nada. Me sinto assim também com os meus pacientes, fico sem saber o que fazer. Até com o meu marido, sou uma impostora. Não tenho tempo para ele. Enquanto ele vê um filme, por exemplo, fico fazendo o registro dos meus atendimentos.

Terapeuta: Você sempre se ocupa de muita coisa. Mal termina algo, você já começa outra coisa. Antes mesmo de sair de um emprego, já começou outro projeto. E agora você está fazendo o mesmo com os cursos de pós-graduação. Você sempre fez isso?

Paciente: Sim, aprendi a ler com 4 anos, com 13 anos já estava no Ensino Médio. E sempre fui uma ótima aluna. Mas eu não estava preparada emocionalmente para isso.

Terapeuta: O que vem acontecendo com você começou cedo. Você gostaria de conversar com você a respeito disso? Lembra que eu te disse que esse método se chama Psicoterapia da Relação?

Paciente: Sim, quero.

Terapeuta no papel da paciente (duplo-espelho): Eu sou você agora. Por que você foi inventar esse curso agora? Nem terminou o outro!

Paciente: Mas eu vou dar conta. Não vale a pena trancar o novo.

Terapeuta no papel da paciente (duplo-espelho): Você diz que vai dar conta, mas não estamos nem conseguindo ser boa esposa. Não temos tempo para o Paulo (nome fictício).

Paciente: Mas sempre fiz muita coisa e dei conta.

Terapeuta no papel da paciente (duplo-espelho): Mas agora não está dando conta. O que vamos fazer?

Paciente: Eu vou me organizar mais. Vou acordar mais cedo. Vai dar certo.

Terapeuta no papel da paciente (duplo-espelho): E tem de fazer bem feito. Tem de sempre fazer tudo e bem feito! Paciente: É verdade.

Terapeuta: Voltei a ser a sua terapeuta. Você quer falar mais alguma coisa para você??

Paciente: Não.

No compartilhar, a paciente percebeu que desde os 4 anos construiu uma crença, um padrão de comportamento que tem de fazer muita coisa, tem de dar conta de tudo e fazer tudo bem feito, senão ela se sente mal como uma impostora. Ela disse que estava pensativa com tudo o que descobriu na sessão. Fiz uma pergunta para ser respondida em outro momento: o que fazer para modificar essa crença, esse padrão? As respostas não surgem imediatamente após uma dramatização. Muitas vezes, a catarse de integração (Moreno, 1993) - que é a possibilidade, através da dramatização, de colocar o seu mundo interno "para fora", desorganizar as estruturas conflitivas e reorganizá-las de forma harmônica — passa pelo processo de percepção, elaboração e resolução. 


\section{PRÓXIMOS PASSOS}

A pandemia nos trouxe, como país, o desafio social de amparar milhões de brasileiros em situação de vulnerabilidade econômica; o desafio, na saúde coletiva, de propiciar atendimento adequado aos infectados pelo coronavírus; o desafio tecnológico de nos conectarmos com qualidade com o maior número de pessoas; e, por fim, o desafio dos psicoterapeutas e, em especial, com relação a este artigo, dos psicodramatistas, que tiveram de ser espontâneos-criativos para fazerem atendimentos de qualidade e eficazes no apoio psicológico a seus pacientes. Como será o depois, não sabemos. Este trabalho vem se unir a vários outros na busca de respostas compartilhadas em processo de cocriação com os outros colegas do Psicodrama, para desenvolver este novo papel da atualidade: psicodramatista on-line.

\section{AGRADECIMENTOS}

Não se aplica.

\section{DISPONIBILIDADE DE DADOS DE PESQUISA}

Todos os dados foram gerados ou apresentados neste estudo.

\section{FINANCIAMENTO}

Não se aplica.

\section{REFERÊNCIAS}

Barbeiro, F. S., \& Reis, M. E. B. T. (2018). Psicoterapia Online: Novo Lugar Para A Clínica? Anais do $1^{\circ}$ Congresso do Programa de Pós-Graduação em Psicologia da UEL (pp. 36-40).

Bustos, D. M. (2005). O psicodrama: Aplicaçôes da técnica psicodramática (3a ed.). Ágora.

Conselho Federal de Psicologia (2018). Resolução CFP n. 11/2018. Regulamenta a prestação de serviços psicológicos realizados por meios de tecnologias da informação e da comunicação e revoga a Resolução CFP n. 11/2012.

Conselho Federal de Psicologia (2020). Resolução CFP n. 04/2020. Dispõe sobre regulamentação de serviços psicológicos prestados por meio de Tecnologia da Informação e da Comunicação durante a pandemia do COVID-19.

Cukier, R. (2018). Psicodrama bipessoal: Sua técnica, seu terapeuta e seu paciente (6ª ed.). Ágora.

Fadden, G. (2002). Research update: Psychoeducational family interventions. Journal of Family Therapy, 20(3), 293309. https://doi.org/10.1111/1467-6427.00088

Fleury, H. J. (2020). Psicodrama e as especificidades da psicoterapia on-line. Revista Brasileira de Psicodrama, 28(1), 1-4. https://doi.org/10.15329/2318-0498.20203

Fonseca, J. (2008). Psicodrama da Loucura: Correlaçôes entre Buber e Moreno (7a ed.). Ágora.

Fonseca, J. (2010). Psicoterapia da relação: elementos de psicodrama contemporâneo. Ágora.

Fonseca, J. (2018). Essência e personalidade: Elementos de psicologia relacional. Ágora.

Joint Task Force for the Development of Telepsychology Guidelines for Psychologists (2013). Guidelines for the practice of telepsychology. The American psychologist, 68(9), 791-800. https://doi.org/10.1037/a0035001

Judge, A. B., Abeles, N., Davis, S. P., Adam-Terem, R., \& Younggren, J. N. (2011). Report from The Society for the Advancement of Psychotherapy Task Force on Telepsychotherapy. http://www.societyforpsychotherapy.org/report-taskforce-telepsychotherapy.

Moreno, J. L. (1993). Psicodrama (9a ed.) (Álvaro Cabral, Trad.). Cultrix. (Obra original publicada em 1946). 